\title{
SMART MONITORING OF BENZENE THROUGH AN URBAN MOBILE PHONE NETWORK
}

\author{
LUCA DALLA VALLE ${ }^{1}$, ELENA CRISTINA RADA ${ }^{1}$, MARCO RAGAZZI $^{1} \&$ MICHELE CARAVIELLO $^{2}$ \\ ${ }^{1}$ Department of Civil Environmental and Mechanical Engineering, University of Trento, Italy. \\ ${ }^{2}$ Telecom Italia, Joint Open Labs, Trento, Italy.
}

\begin{abstract}
Benzene is one of the main air pollutants because of its dispersion throughout the territory and its carcinogenicity. Thus, in accordance with the current European Directive 2008/50/EC, benzene is monitored punctually in EU countries. In this context, the University of Trento and Telecom Italia, in response to specific studies, have developed an approach that could be conceptually divided into two phases: (A) the first one assumes the distribution of low-cost sensors to a part of the local population for the monitoring of carbon monoxide that, in this case, could be used for its indirect role of tracer. These sensors, compatible with smartphones and therefore with the network, allow acquiring remotely a huge amount of data that could be used to create detailed maps of air quality after a process of validation/selection (based on algorithms already developed by Telecom). (B) The second phase is based on the fact that the correlation between carbon monoxide and benzene is scientifically proven in homogeneous areas; thus, through an ad hoc study, it is possible to set a specific correlation carbon monoxide - benzene for each pre-selected area. The result of this method is quantitative information on exposure of the resident population to benzene with a detail not reachable through conventional approaches and suitable for an enhanced activity of decision makers. For a full scale exploitation, this approach requires an economic effort achievable only with external financing as, presently, the official monitoring activity allows only conventional actions.
\end{abstract}

Keywords: correlation $\mathrm{CO}-\mathrm{C}_{6} \mathrm{H}_{6}$, human exposure, low cost and portable sensors, new approach, smart monitoring.

\section{INTRODUCTION}

Air pollution is one of the major environmental health problems to which about 7 millions of premature deaths are ascribable worldwide. This finding confirms that air pollution is now the world's largest single environmental health risk [1-5]. In particular, the same WHO estimates approximately $80 \%$ of premature deaths related to air pollution are caused by ischemic heart disease and stroke, $14 \%$ of deaths are due to chronic lung disease or acute infections of the lower respiratory tract, and finally, the $6 \%$ of deaths are due to lung cancer. Related studies have shown that these diseases are related to several factors, such as the consumption of tobacco combined to air pollution promote lung cancer. These studies also showed some of these deaths could be prevented improving air quality or reducing the consumption of tobacco [6].

The problem of air pollution is still related to sources that could not be managed and controlled by the individuals (transports, waste, construction, agriculture, etc.), it is why in recent years, especially in advanced countries, a specific legislation focused on air quality standards has been developed. For example in European countries, enacting the European Directive $50 / 2008$, it was necessary also to establish monitoring networks in order to control the concentrations of the main pollutants. This methodology employs expensive equipment that need 
fixed locations or dedicated mobile stations. Then the collected data are used to extrapolate the air quality throughout the related area, only for some of the pollutants monitored. However, with this method, there are pollutants, with significant impacts on health and environment, excluded from the air quality analysis. It is important to note the general environment reveals different and multiple air contaminants' concentrations. The advantage of the mobile platforms instead of traditional monitoring station is the ability to acquire air quality data referred to a wider area. This is very important considering for example the different effect regarding air pollution, in space and time, referred to the primary emissions and secondary formation. Another important factor to take in consideration is the high level of temporal changes that affect generally the air in our cities [7]. The mobile measurements consent to monitor better this kind of pollutant data also to a micro-scale level of variation. The mobile monitoring could also be used to collect data on a wider level in term of space and time [8] and need to be taken into account on a European level for future recommendations regarding the air quality to the related countries.

The objective of this study is to create spatial and temporal high-resolution maps of a determined pollutant currently measured in few fixed stations in the referred area. With this kind of monitoring, it is not possible to extrapolate the concentrations in the related area. For the purpose of this study, the polluting substance chosen is benzene $\left(\mathrm{C}_{6} \mathrm{H}_{6}\right)$ : a colourless hydrocarbon, with a characteristic odour, highly inflammable, in volatile liquid form, able to evaporate quickly. Its dispersion in the atmosphere, being a natural compound of petroleum and its derivatives, is due for the most part to the vehicle traffic (over 80\%), as used as antiknock in gasoline [9]. The hazard level of benzene is due to its strong toxicity; in facts, its carcinogenicity was classified belonging to the group 1 by the International Agency for Research on Cancer [10]. The substances included in this group have been proved to be carcinogenic to humans, and in this regard the IARC specifies [11]: this category is used when there is sufficient evidence of carcinogenicity in humans. Exceptionally, an agent may be placed in this category when evidence of carcinogenicity in humans is less than sufficient but there is sufficient evidence of carcinogenicity in experimental animals and strong evidence in exposed humans that the agent acts through a relevant mechanism of carcinogenicity.

If inhaled in high concentrations it could cause death; at lower concentrations may still cause disorders such as drowsiness, headache, dizziness, tachycardia, confusion or loss of consciousness [9].

\section{MATERIAL AND METHODS}

The idea that is gaining ground in many academic environments is a denser monitoring network, based on devices with lower costs and better distributed on the territory. Moreover, given the prevalence of smartphones, it is felt the need to have free and real time data access. All this could lead to a raise awareness of the people on air pollution, an issue of great importance and relevance, as well of public interest.

In this context, the University of Trento and Telecom Italia have developed an approach based on low-cost and portable sensors that allows the collection and elaboration of polluting data with a high spatial resolution and in real time. This method can be conceptually divided into two phases.

\subsection{Phase A: SecondNose}

The SecondNose system is composed by four components: an air pollution sensor, an Android mobile phone application, a backend with collection and analytics components and a web application to visualize the data [12]. 


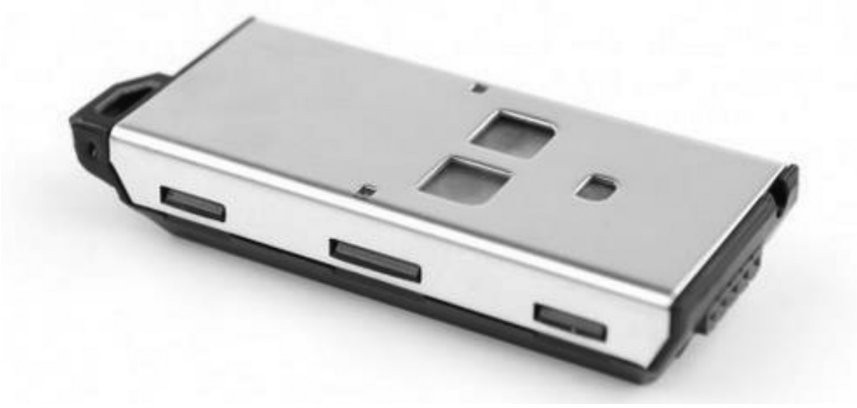

Figure 1: Portable multi-sensor Sensordone ${ }^{\mathrm{TM}}$.

Eighty portable multi-sensor Sensordrone ${ }^{\mathrm{TM}}$ (Fig. 1) were distributed among the population of Trento (Italy). This detector was produced from Sensorcon, an American company with over ten years of experience in the design, production and integration of environmental sensors. Such tool, inter - connectable with smartphones through special applications, is equipped with various types of sensors such as precision gases, oxidizing gases, reducing gases, temperature, humidity, pressure, infrared temperature, capacitive proximity, intensity of colour (red, green and blue) and brightness. Sensordrone ${ }^{\mathrm{TM}}$ 's dimensions are $6.78 \times 2.80$ $\times 1.24 \mathrm{~cm}^{3}$.

This tool provides a carbon monoxide concentration measurement with a quite good precision (resolution: $1 \mathrm{ppm}$; range: $0-2,000 \mathrm{ppm}$; accuracy: $\pm 10 \%$ of reading; response time: 10-20 seconds to reach $90 \%$ of final signal; [13]), but on the other hand with not satisfactory reliability for the criteria required by the current law and regulations. Need to be underlined that the purpose of this paper is the presentation of an innovative approach in the field of the air quality monitoring and not an accomplished method, at least regarding the instrumentation. Through an Android mobile phone application, it is possible for the users to visualize a real-time data collection from the ambient sensor Sensordrone ${ }^{\mathrm{TM}}$. The application provides real-time feedback reporting: the temperature detected, the atmospheric pressure trend, that is, based on the last ten samples of pressure, and the overall air quality, on a 5-values scale based on EPA AQI colouring scheme. It is also necessary, for a proper analysis of the data, to distinguish if the sensor is located in indoor or outdoor environment. For this purpose, Telecom has developed a prototype, still to be finalized, based on an algorithm that could differentiate the signals between indoors and outdoors environments.

Since April 2014, for few months, data had been remotely collected, with an interval of five minutes and a daily total of 30k of data, values related to: temperature, pressure and the concentrations measured from the Sensordrone ${ }^{\mathrm{TM}}$ Precision gas sensor, pre-calibrated on carbon monoxide (CO). As explained better in the second stage, the $\mathrm{CO}$ is used in an indirect manner as a tracer for benzene. The web application provides access to the aggregated data of the last seven days collected from the reading of the users involved. In particular, the CO concentration levels, geo referenced using GPS, are inserted into a map and spatialized on the area considered after a process of validation / selection based on algorithms developed by Telecom (Fig. 2).

There is therefore the opportunity to view the history of personal measurements and, anonymously, the ones collected by other users. It is also possible to have the detailed air quality maps referred to the pollutant considered. 


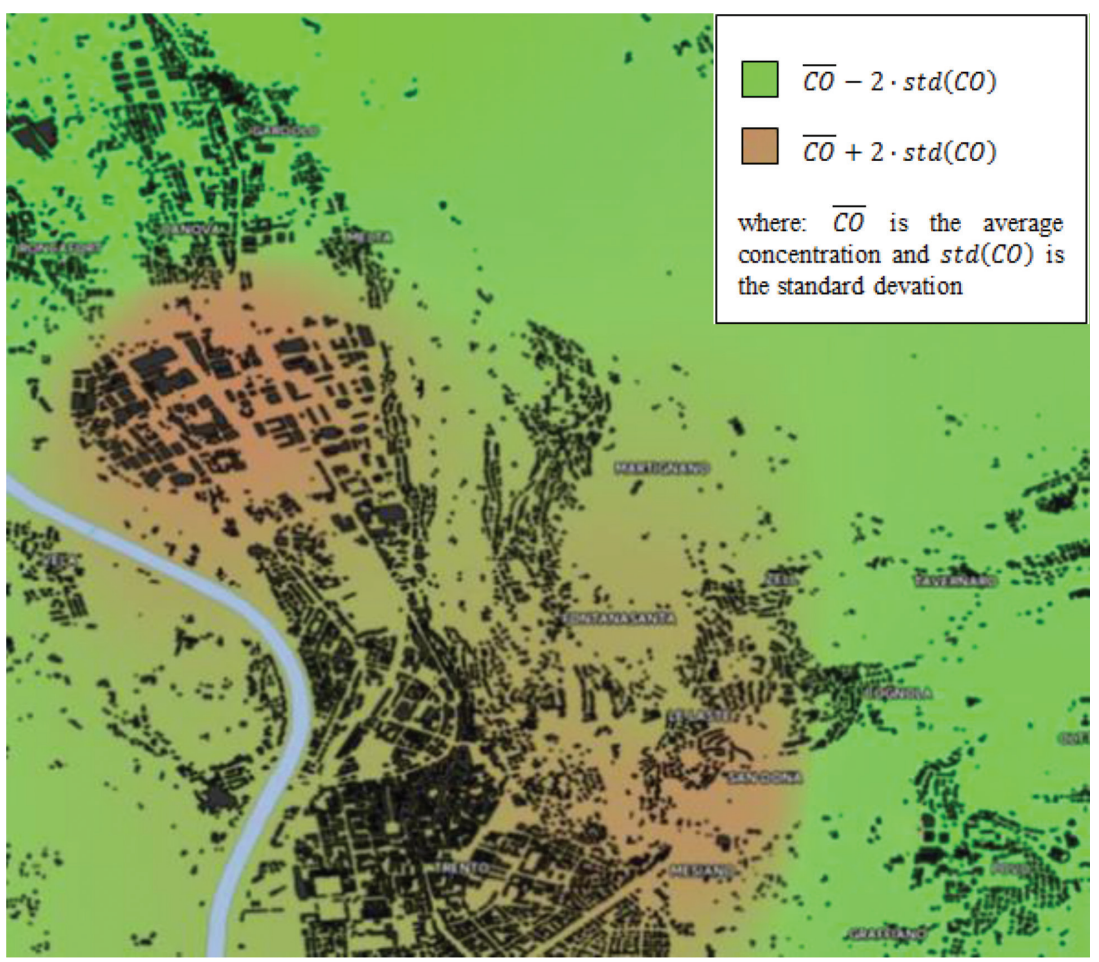

Figure 2: Example of a monoxide carbon's concentration map.

\subsection{Phase B: Correlation carbon monoxide - benzene}

The correlation between carbon monoxide and benzene has been scientifically proven: there are many studies recognizing trends of similar concentration for the two pollutants in homogeneous areas $[14,15]$. This correlation is due to the fact that the two pollutants' main sources of emission are the same [14] among which: the vehicular traffic, the combustion of the wood and the tobacco's smoke. Another correlation's factor between the concentrations of carbon monoxide and benzene has been found: the atmospheric lifetime of benzene, that could last for several days [16]. That means that benzene is removed from the urban environment by meteorological processes, which is how CO is mostly removed [17].

Through an ad hoc study, it is possible to set a specific correlation carbon monoxide - benzene for each pre-selected area. It is possible to establish a relationship of proportionality between the two pollutants considered, starting by measured data in the fixed monitoring stations (determined station as required by the European Directive 50/2008). This relationship could be explicated through different expressions depending by the choices made during the study of the pollutant concentration's data. This is also due to some gaps at regulation and law level to a precise procedure in this regard.

Some Italian Regional Agencies for Environmental Protection (ARPA) have already analysed and used the correlation between carbon monoxide and benzene for further deductions and observations. In the Table 1, some correlation - relationships could be observed as reported from different Italian ARPA. Uniformity as already reported above is not present in the formulation of this table. 
Table 1: Some ARPA's correlation between $\mathrm{CO}-\mathrm{C}_{6} \mathrm{H}_{6}$.

\begin{tabular}{llcc}
\hline Correlation $\left.\mathrm{CO}-\mathrm{C}_{6} \mathrm{H}_{6}{ }^{*}\right)$ & \multicolumn{1}{c}{ ARPA } & Year & References \\
\hline$\left[\mathrm{C}_{6} \mathrm{H}_{6}\right] \approx 2 *[\mathrm{CO}]$ & Emilia Romagna & 1999 & {$[18]$} \\
{$\left[\mathrm{C}_{6} \mathrm{H}_{6}\right]=3.465 *[\mathrm{CO}]-0.3616$} & Piemonte & 2001 & {$[19]$} \\
{$\left[\mathrm{C}_{6} \mathrm{H}_{6}\right]=2.017817 *[\mathrm{CO}]$} & Puglia & 2007 & {$[20]$} \\
\hline
\end{tabular}

$\left.{ }^{*}\right)\left[\mathrm{C}_{6} \mathrm{H}_{6}\right]$ and $[\mathrm{CO}]$ are respectively expressed in $\mu \mathrm{g} / \mathrm{m}^{3}$ and $\mathrm{mg} / \mathrm{m}^{3}$

Once got the correlation- relationship between carbon monoxide and benzene, it is sufficient to apply it to the monoxide carbon concentrations' data measured by Sensordrone ${ }^{\mathrm{TM}}$. Applying this method air quality's maps could be provided related to benzene at high spatial and temporal variability.

\section{RESULTS AND FUTURE DEVELOPMENTS}

The result of the approach developed jointly by the University of Trento and Telecom Italy is a quantitative information on the exposure of the resident population to carcinogenic substance as benzene. This approach, extendible to other pollutants, primarily allows to sensitize and erudite the population on an issue very important as the air quality is. This theoretically could lead to improve the life quality of the population involved, limiting as much as possible the exposure to certain pollutants. At this regard, changing the route of the journey or minimizing the permanence in the areas with the highest concentrations could be practical examples. Moreover, the authorities and the decision makers could find in so detailed information and data analysis a useful tool to understand which are the critical areas. This could help also to define more appropriated solutions and plans in order to reduce pollutants' exposure. However, such considerations make sense only with regard to very detailed information that nowadays is impossible to get from conventional approaches. On the other hand, it is clear that the approach here presented would like to be an example of an innovative method and not a concrete proposal. For a full scale exploitation further studies are needed, possible through an economic effort achievable only with external financing. In fact there are many aspects that would deserve an in-depth analysis, here are illustrated the main ones:

- To develop a sensor with the sensitivity and reliability to ensure this approach could meet the requirements imposed by the relevant law and regulations;

- To establish the sensor density (n. Sensors $/ \mathrm{km}^{2}$ ) useful to obtain a number of data necessary in order to proceed: previously to their validation and then to the spatialization on the related area;

- To study a standard methodology in order to set a correlation $\mathrm{CO}-\mathrm{C}_{6} \mathrm{H}_{6}$ starting from fixed stations' data, also for other pollutants;

- To study a methodology able to define the extension of the area within which the ratio of carbon monoxide - benzene could be considered homogeneous;

- To study an algorithm that allows users (of sensors) passing close to the fixed monitoring stations to reset the baseline's sensor that could provide certainly more precise values.

In conclusion, also with the above mentioned in-depth analysis, this approach could be thought as a support and a complement to the possible gaps of the current legislation. This 
could help in the future to develop an air quality mapping with a higher spatial and temporal variability.

\section{REFERENCE}

[1] 7 million premature deaths annually linked to air pollution, World Health Organisation (WHO), available at: http://www.who.int/mediacentre/news/releases/2014/air-pollution/en/

[2] Schiavon, M., Redivo, M., Antonacci, G., Rada, E.C., Ragazzi, M., Zardi, D. \& Giovannini, L., Assessing the air quality impact of nitrogen oxides and benzene from road traffic and domestic heating and the associated cancer risk in an urban area of Verona (Italy). Atmospheric Environment, 120, pp. 234-243, 2015. http://dx.doi.org/10.1016/j.atmosenv.2015.08.054

[3] Rada, E.C., The sustainable city and air pollution. WIT Transactions on Ecology and the Environment, 191, pp. 1369-1380, 2014. http://dx.doi.org/10.2495/SC141152

[4] Schiavon, M., Antonacci, G., Rada, E.C., Ragazzi, M. \& Zardi, D., Modelling human exposure to air pollutants in an urban area. Revista de Chimie, 65(1), pp. 61-64, 2014.

[5] Rada, E.C., Ragazzi, M., Brini, M., Marmo, L., Zambelli, P., Chelodi, M. \& Ciolli, M., Perspectives of low-cost sensors adoption for air quality monitoring. UPB Scientific Bulletin, Series D, 74(2), pp. 243-250, 2012.

[6] Ambient (outdoor) air quality and health, World Health Organisation (WHO), available at: http://www.who.int/mediacentre/factsheets/fs313/en/

[7] Van den Bossche, J., Peters, J., Verwaeren, J., Botteldooren, D., Theunis, J. \& De Baets, B., Mobile monitoring for mapping spatial variation in urban air quality: Development and validation of a methodology based on an extensive dataset. Atmospheric Environment, 105, pp. 148-161, 2015.

http://dx.doi.org/10.1016/j.atmosenv.2015.01.017

[8] Kuhlbusch, T.A., Quincey, P., Fuller, G.W., Kelly, F., Mudway, I., Viana, M., Querol, X., Alastuey, A., Katsouyanni, K., Weijers, E., Borowiak, A., Gehrig, R., Hueglin, C., Bruckmann, P., Favez, O., Sciare, J., Hoffmann, B., EspenYttri, K., Torseth, K., Sager, U., Asbach, C. \& Quass, U., New Directions: the future of European urban air quality monitoring. Atmospheric Environment, 87, pp. 258-260, 2014.

[9] Benzene; United States Environmental Protection Agency (USEPA), available at: http:// www3.epa.gov/airtoxics/hlthef/benzene.html

[10] International Agency for Research on Cancer (IARC), Chemical agents and related occupations - vol. 100F - A review of human carcinogens, IARC monographs on the evaluation of carcinogenic risks to humans, Lyon, 2012.

[11] Preamble; International Agency for Research on Cancer (IARC), available at: http:// monographs.iarc.fr/ENG/Preamble/CurrentPreamble.pdf

[12] Leonardi, C., Secondnose: an air quality mobile crowdsensing system, Proceeding of the 8th Nordic Conference on Human-Computer Interaction: Fun, Fast, Foundational (NordiCHI '14), eds. B. Lepri, A. Cappellotto, F. Antonelli \& M. Caraviello, Association for Computing Machinery (ACM): Finland, pp. 1051-1054, 2014.

[13] Developer Guide and Sensor Specs, Sensorcon, available at: http://sensorcon.com/solutions-support/product-support/user-manuals-data-sheets 
202 Urban Regeneration and Sustainability

[14] National Research Council of the National Academies (NRC), Managing Carbon Monoxide Pollution in Meteorological and Topographical Problem Areas, The National Academies Press: Washington D.C., 2003.

[15] Von Schneidemesser, E., Monks, P.S. \& Plass-Duelmer, C., Global comparison of VOC and CO observations in urban areas. Atmospheric Environment, 44, pp. 5053-5064, 2010.

[16] Air quality in Europe - 2012 report; European Environment Agency (EEA), available at: www.eea.europa.eu/publications/air-quality-in-europe-2012/at_download/file

[17] Benzene; United States Environmental Protection Agency (USEPA), available at: http:// www3.epa.gov/otaq/regs/toxics/airtox1b.pdf

[18] Rapporto annuale sulla qualità dell'aria Comune di Reggio Emilia; ARPA Emilia Romagna, available at: http://www.arpa.emr.it/cms3/documenti/_cerca_doc/aria/aria_ re/sinmet_rapparia_2000_comunere.pdf

[19] Campagna di monitoraggio qualità dell'aria, Comune di Verbania; ARPA Piemonte, available at: http://www.comune.verbania.it/content/download/4719/53781/file/ Relazione_ARPA_2001_I.pdf

[20] Campagna di monitoraggio della qualità dell' aria con laboratorio mobile; ARPA Puglia, available at: https://www.google.it/url?sa=t\&rct=j\&q=\&esrc=s\&source=web \&cd=2 $\&$ cad $=$ rja $\&$ uact $=8 \&$ ved $=0$ ahUKEwjulrekqffLAhXJiCwKHbrYC0sQFgghMAE\&url=http $\% 3 \mathrm{~A} \% 2 \mathrm{~F} \% 2 \mathrm{Fwww}$.arpa.puglia.it $\% 2 \mathrm{Fc} \% 2 \mathrm{Fdocument}$ library\%2Fget_file \%3Fuuid\%3Dfba4959d-3589-438a-a4fa-15730ca48556\%26groupId\%3D13879\&usg=AFQjCNHOuYVAw5F-zzYuFq03R6eVRv8zDw 